\title{
Magnetic hardening mechanism study in FePt thin films
}

\author{
C. M. Kuo, P. C. Kuo, and H. C. Wu \\ Institute of Materials Science and Engineering, National Taiwan University, Taipei 107, Taiwan
}

Y. D. Yao ${ }^{\mathrm{a})}$

Institute of Physics, Academia Sinica, Taipei 115, Taiwan

C. H. Lin

Department of Materials Science and Engineering, National Tsing Hua University, Hsinchu 300, Taiwan

$\mathrm{Fe}_{100-x} \mathrm{Pt}_{x}$ alloy thin films with $x=25-67$ at. \% were prepared by dc magnetron sputtering on naturally oxidized Si substrates. Effects of film composition, annealing temperature $\left(300-650{ }^{\circ} \mathrm{C}\right)$, annealing time (5-120 $\mathrm{min}$ ), and cooling rate (furnace cooling or ice water quench cooling) on the magnetic properties were investigated. Optimum conditions for saturation magnetization and coercivity of the $\mathrm{Fe}_{100-x} \mathrm{Pt}_{x}$ alloy films were found with $x=50$ at. $\%$, annealed at $600{ }^{\circ} \mathrm{C}$ for $30 \mathrm{~min}$ and cooled by ice water quenching. Our experimental data suggests that the magnetic hardening in $\mathrm{Fe}_{100-x} \mathrm{Pt}_{x}$ alloy thin films is mainly due to the fct $\gamma_{1}$ - FePt phase and the domain wall pinning effect. The domain nucleation mechanism is dominated in samples with furnace cooling; the domain wall pinning mechanism dominates in samples cooled with ice water quenching. (C) 1999 American Institute of Physics. [S0021-8979(99)60108-6]

\section{INTRODUCTION}

Recently, considerable attention has been focused on the magnetic properties of the $\mathrm{FePt}$ alloy because it has very high magnetocrystalline anisotropy energy $\left(K u \cong 7 \times 10^{7}\right.$ ergs $/ \mathrm{cm}^{3}$ ), high coercivity, good corrosion resistance, and large energy products $(\mathrm{BH})_{\max } \cdot{ }^{1-3}$ It is well-suited application in magnetic recording media and various micromagnetic devices. Zhang et $\mathrm{al}^{2}{ }^{2}$ has indicated that the magnetic properties of the FePt alloy strongly depend on its composition, as well as heat-treatment conditions.

\section{EXPERIMENT}

$\mathrm{Fe}_{100-x} \mathrm{Pt}_{x}(x=25-67$ at. \%) alloy thin films were deposited on a naturally-oxidized silicon wafer substrate at room temperature by dc magnetron sputtering. The substrate was rotated in order to get uniform composition. A mosaic target consisting of a high purity iron disk $(99.99 \%)$ overlaid with high purity platinum pieces $(99.99 \%)$ was used. This arrangement provides a wide range of effective target compositions and therefore a wide range of film compositions. The deposition rate was about $0.3 \mathrm{~nm} / \mathrm{s}$. The base pressure in the sputtering chamber was $5 \times 10^{-7}$ Torr, and the argon pressure was fixed at 5 mTorr. Film thickness was kept at $200 \mathrm{~nm}$. For annealing studies, the as-deposited films were sealed in quartz capsules and heat-treated in a vacuum of 1 $\times 10^{-6}$ Torr.

Magnetic properties of the films were measured with a vibrating sample magnometer (VSM) and a superconducting quantum interference device (SQUID). The microstructure of the films was characterized by a JOEL 100 CX transmission electron microscopy (TEM), and the phases of the film were examined by an x-ray diffractometer with $\mathrm{Cu} K \alpha$ radiation. The average grain size of the film was measured by the TEM

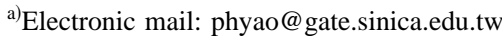

bright field image. Composition and homogeneity of the films were determined by energy disperse $\mathrm{x}$-ray diffractometer. The thicknesses of the films were measured by an $\alpha$ step.

\section{RESULTS AND DISCUSSION}

Figure 1 shows the saturation magnetization $M_{s}$ and the coercivity $H_{c}$ at room temperature for as-deposited and $500{ }^{\circ} \mathrm{C}$-annealed $\mathrm{Fe}_{100-x} \mathrm{Pt}_{x}$ films as functions of Pt content $x$ between 25 and 67 at. \%. A soft magnetic $\gamma$-FePt phase and low $H_{c}$ near 20 Oe were observed in as-deposited films. The $M_{s}$ decreases with increasing Pt content. After annealing, we observed that only the $\mathrm{Fe}_{100-x} \mathrm{Pt}_{x}$ films with $x=50$ showed that $M_{s}$ decreased very little and $H_{c}$ increased abruptly. In general, the decrease in $M_{s}$ after annealing for samples ex-

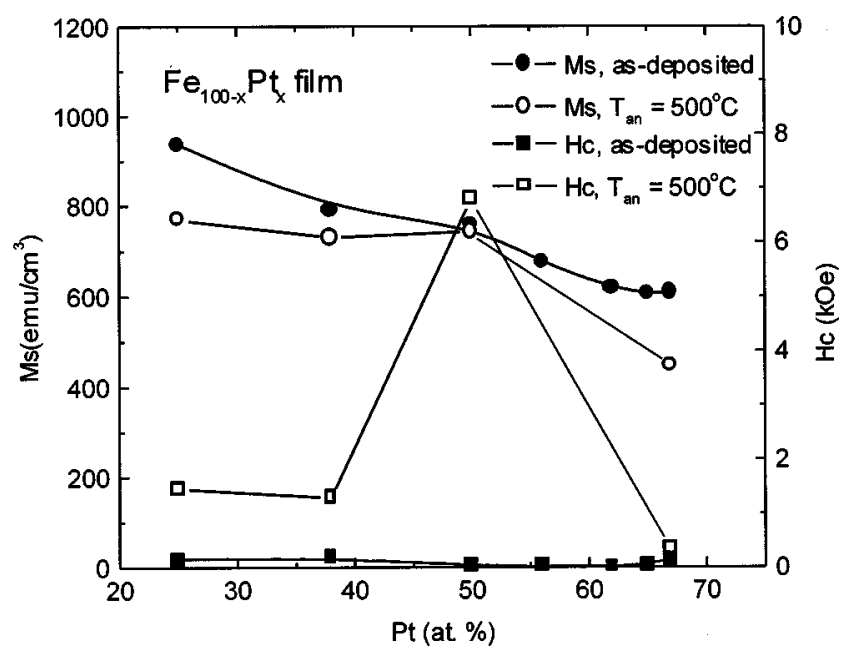

FIG. 1. $M_{s}$ and $H_{c}$ at room temperature for as-deposited and $500{ }^{\circ} \mathrm{C}$ annealed $\mathrm{Fe}_{100-x} \mathrm{Pt}_{x}$ films as a function of Pt concentration $x$ between 25 and 67 at \%. The film thickness is $200 \mathrm{~nm}$. 


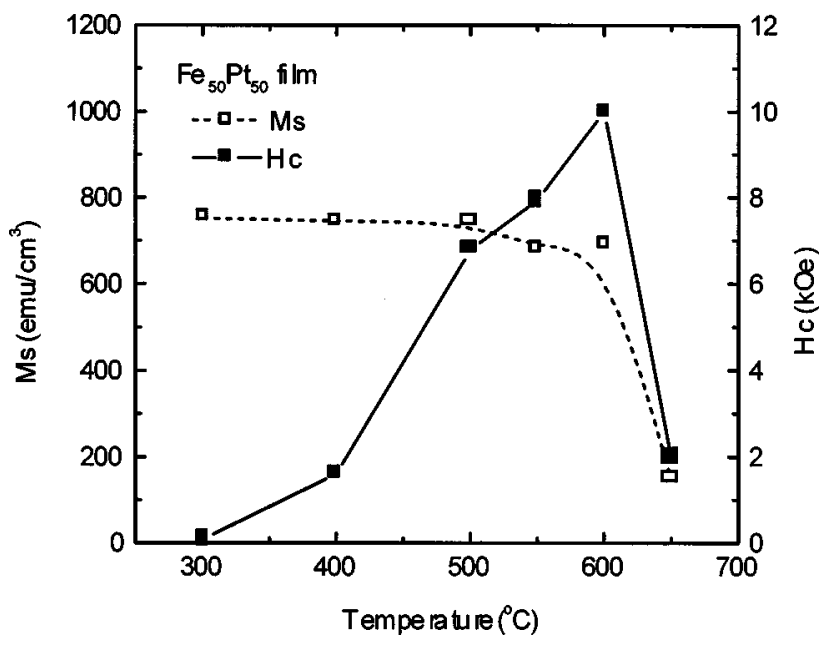

FIG. 2. $M_{s}$ and $H_{c}$ as functions of the annealing temperature for $\mathrm{Fe}_{50} \mathrm{Pt}_{50}$ films with the annealing time of $30 \mathrm{~min}$. The film thickness is $200 \mathrm{~nm}$.

cept that with $x=50$ is attributed to the formation of either ordered $\mathrm{FePt}_{3}$ or $\mathrm{Fe}_{3} \mathrm{Pt}$ phases, which show lower $M_{s}$ than $\gamma$-FePt phase. ${ }^{4}$ However, for the sample with $x=50$, it can be explained due to the existence of both $\gamma$ - and $\gamma_{1}$-FePt phases in the sample. From the optimum treatment, we have obtained that the difference of the saturation magnetization between pure fct $\gamma_{1}-\mathrm{FePt}$ phase $\left(M_{s}=680 \mathrm{emu} / \mathrm{cm}^{3}\right)$ and pure $\gamma$-FePt phase $\left(M_{s}=750 \mathrm{emu} / \mathrm{cm}^{3}\right)$ is within $10 \%$. Figure 2 shows the relationships between $M_{s}, H_{c}$, and annealing temperature $T_{\text {an }}$ for ice water quenched $\mathrm{Fe}_{50} \mathrm{Pt}_{50}$ film. The annealing time $t_{\mathrm{an}}$ was kept at $30 \mathrm{~min} . H_{c}$ increased with increasing $T_{\text {an }}$ for $T_{\text {an }}<600{ }^{\circ} \mathrm{C}$, and decreased abruptly with $T_{\text {an }}$ above $600^{\circ} \mathrm{C}$. $M_{s}$ value of the film always decreases with increasing $T_{\text {an }}$, and it decreases abruptly as $T_{\text {an }}$ $>600^{\circ} \mathrm{C}$. The abrupt decrease of both $H_{c}$ and $M_{s}$ is due to the chemical interaction of $\mathrm{FePt}$ layer with a $\mathrm{Si}$ substrate. Figure 3 plots $M_{s}$ and $H_{c}$ as functions of annealing time at

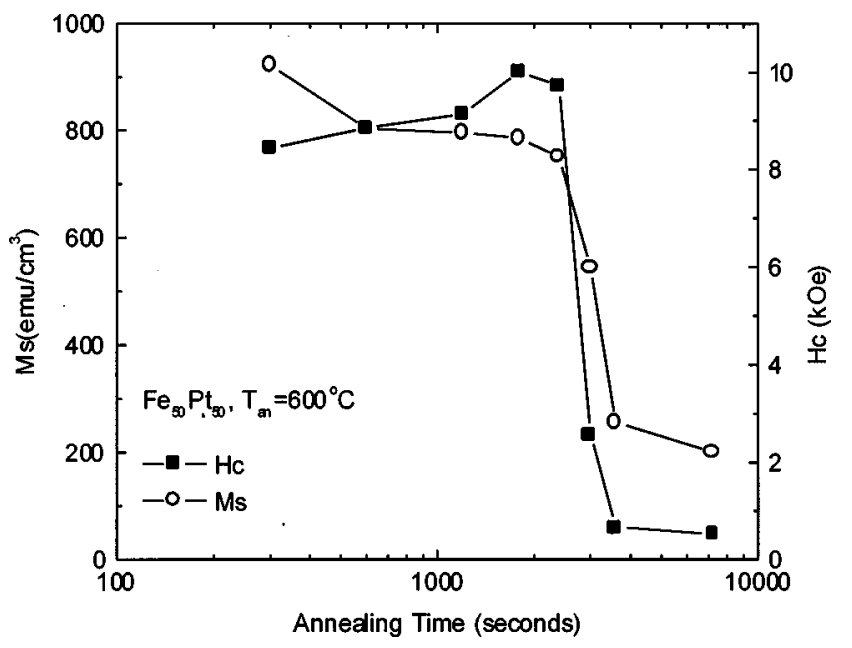

FIG. 3. $M_{s}$ and $H_{c}$ as functions of annealing time for $\mathrm{Fe}_{50} \mathrm{Pt}_{50}$ films with $T_{\text {an }}=600^{\circ} \mathrm{C}$ and annealing time $=30 \mathrm{~min}$.

$T_{\text {an }}=600{ }^{\circ} \mathrm{C}$ for the ice water quenched $\mathrm{Fe}_{50} \mathrm{Pt}_{50}$ film. It is clear that both $M_{s}$ and $H_{c}$ decrease abruptly above $30 \mathrm{~min}$. Figure 4 shows the Auger electron spectroscopy (AES) signal as a function of sputter etching time for $\mathrm{Fe}_{50} \mathrm{Pt}_{50}$ films with (a) as-deposited, (b) $T_{\text {an }}=300^{\circ} \mathrm{C}(30 \mathrm{~min})$, (c) $T_{\text {an }}$ $=600{ }^{\circ} \mathrm{C}(30 \mathrm{~min})$, and $(\mathrm{d}) T_{\text {an }}=650^{\circ} \mathrm{C}(30 \mathrm{~min})$, respectively. It is evident that for $T_{\text {an }}$ above $650^{\circ} \mathrm{C}$, both $\mathrm{Fe}$ and $\mathrm{Pt}$ atoms chemically interact with the $\mathrm{Si}$ substrate heavily. This explains why both $M_{s}$ and $H_{c}$ decrease abruptly above 30 min, as shown in Fig. 3.

According to Yung et al. ${ }^{1}$ and Watanabe, ${ }^{3}$ the origin of the high coercivity of the FePt alloy is related to the degree of the imperfection of the fct $\gamma_{1}$-FePt phase. It is well known that the phase transformation mechanism of $\gamma$-FePt to $\gamma_{1}$-FePt is belong to martensitic phase transformation $\left[A 1(\mathrm{fcc}) \rightarrow L 1_{0}(\mathrm{fct})\right]$ which occurs via a nucleation and
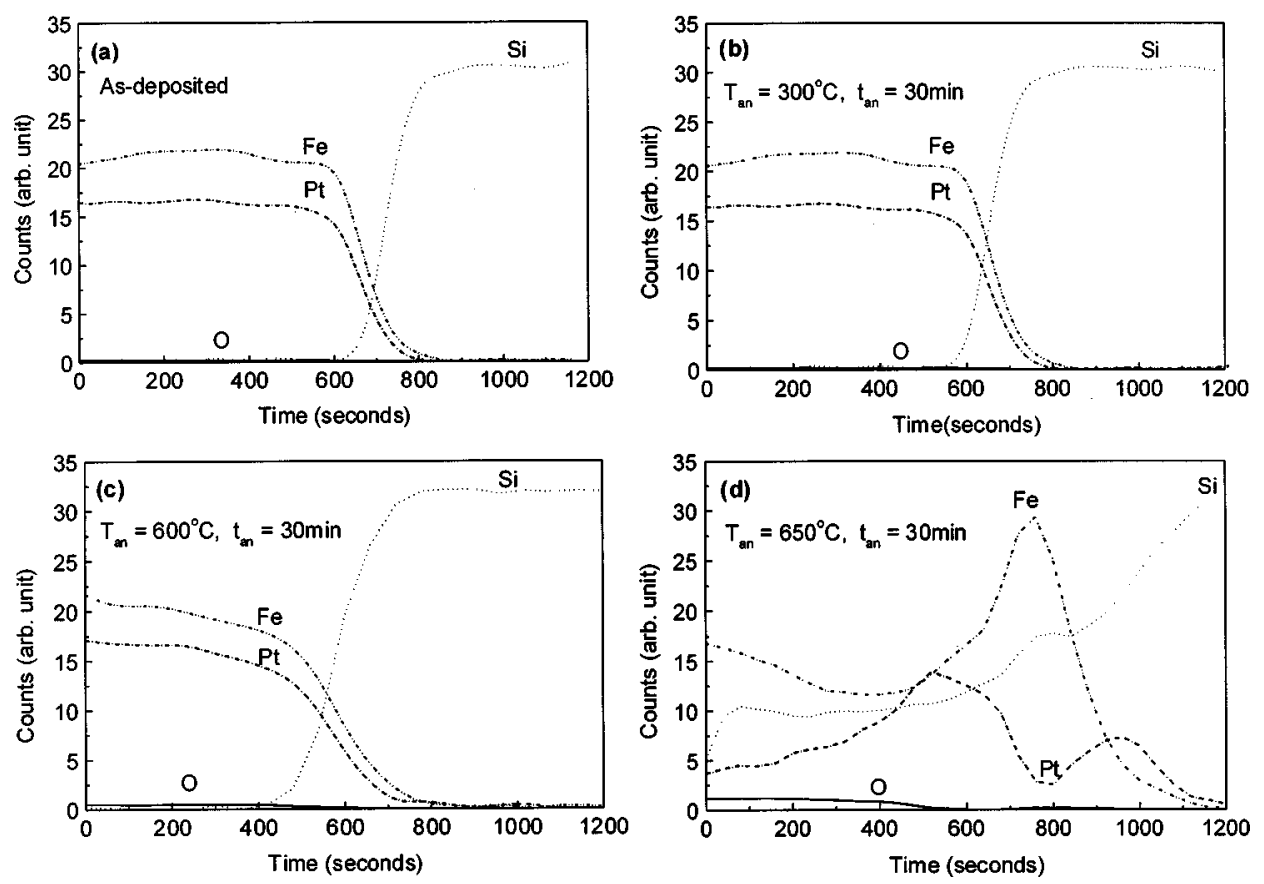

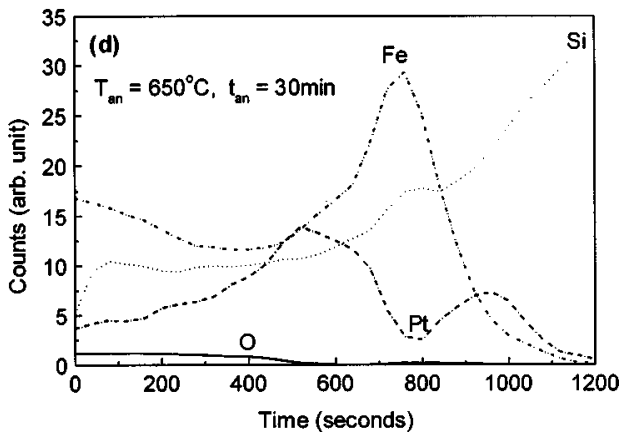

FIG. 4. AES signal as a function of sputter time for $\mathrm{Fe}_{50} \mathrm{Pt}_{50}$ films with (a) as-deposited, (b) $T_{\text {an }}=300{ }^{\circ} \mathrm{C} \quad(30$ $\min )$, (c) $T_{\text {an }}=600{ }^{\circ} \mathrm{C}(30 \mathrm{~min})$, and (d) $T_{\text {an }}=650^{\circ} \mathrm{C}(30 \mathrm{~min})$, respectively. 

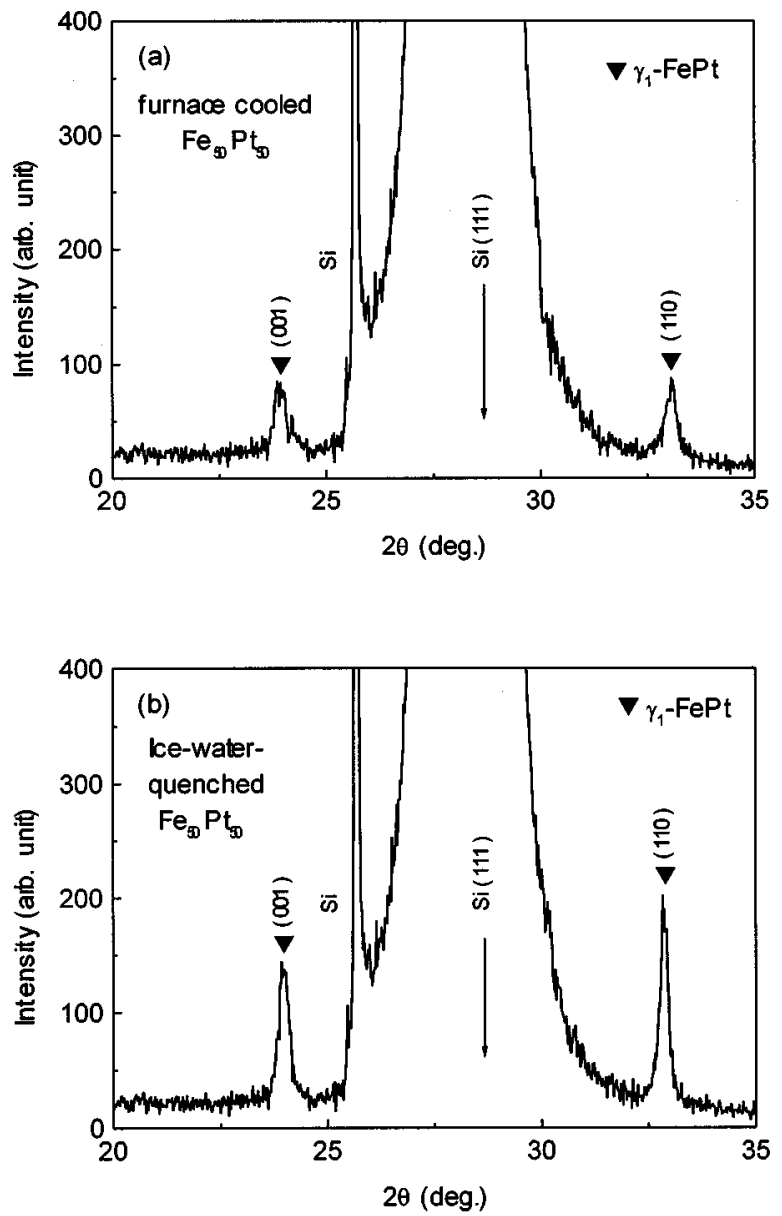

FIG. 5. X-ray diffraction patterns of annealed $\mathrm{Fe}_{50} \mathrm{Pt}_{50}$ films that were (a) furnace cooled and (b) quenched in ice water.

growth process. If cooling rate is infinitely slow, the martensitic phase transformation will not occur. This means that nucleation is dependent on the cooling rate (i.e., it offers the driving force to the nuclei) and it affects the degree of imperfection (i.e., twins, antiphase boundaries etc.). The imperfection of the fct $\gamma_{1}$-FePt phase will cause pinning of magnetic domain wall motion. In order to clarify the origin of high $H_{c}$ in the FePt films, both furnace cooling and ice water quench cooling were studied for $\mathrm{Fe}_{50} \mathrm{Pt}_{50}$ films. Figure 5 shows the $\mathrm{x}$-ray diffraction patterns of $\mathrm{Fe}_{50} \mathrm{Pt}_{50}$ films that were (a) furnace cooled and (b) ice water quenched. By comparing the intensities and nonsymmetry of the fct (001) and the (110) peaks in Figs. 5(a) and 5(b), it is revealed that the high coercivity of the ice water quenched film comes from the increased amount of imperfect fct $\gamma_{1}$-FePt phase, which transformed from the fcc $\gamma$-FePt matrix. From the SQUID $M-H$ loop study the $\mathrm{Fe}_{50} \mathrm{Pt}_{50}$ film after annealing at $600{ }^{\circ} \mathrm{C}$ for $30 \mathrm{~min}$, the "two shoulder" shape in the $M-H$ loop in low fields shows evidence of exchange coupling between the magnetically hard fct $\gamma_{1}$-FePt phase and the soft fcc $\gamma$-FePt phase. ${ }^{5}$ This indicates that a small amount of the soft fcc $\gamma$-FePt phase in films becomes the pinning center of domain wall motion. $(B H)_{\max }$ value of this film is calculated to be about 14 MGOe.
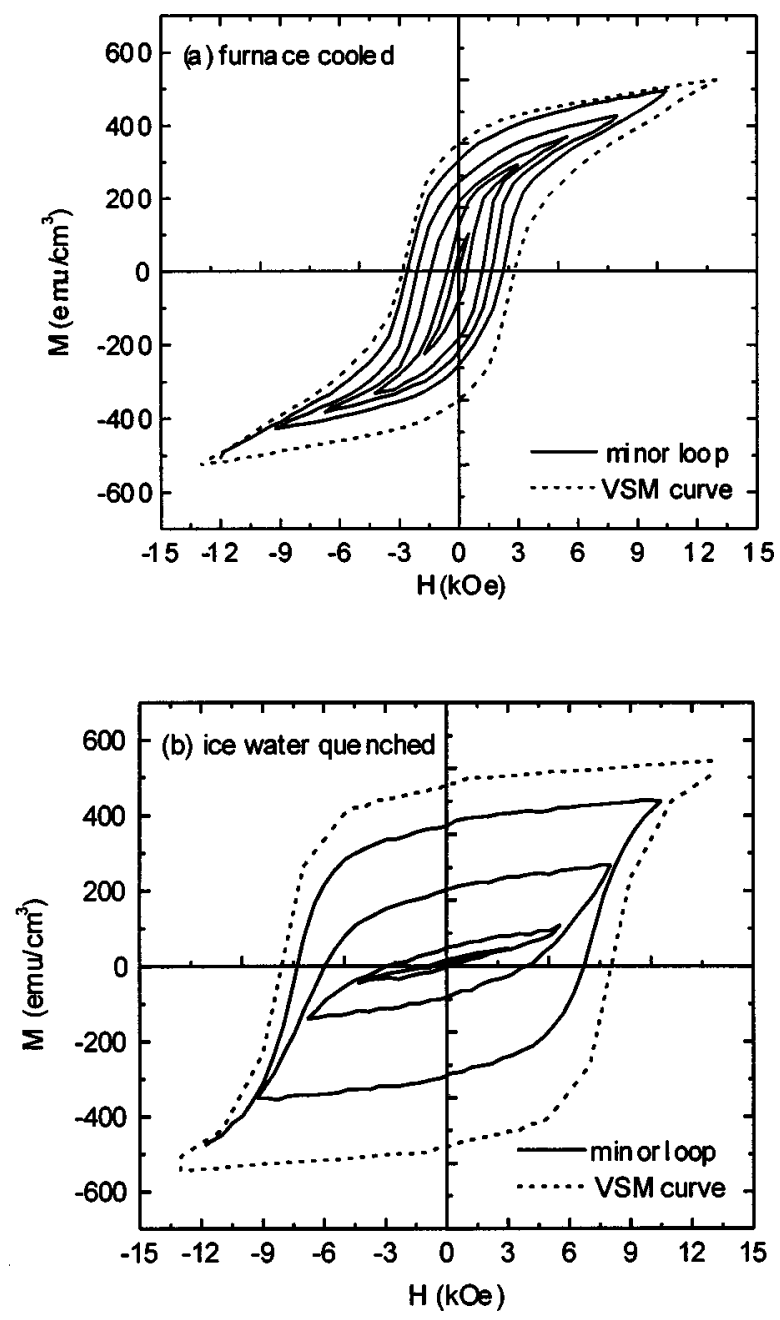

FIG. 6. The continuous minor loops of the $\mathrm{Fe}_{50} \mathrm{Pt}_{50}$ films annealed at $600{ }^{\circ} \mathrm{C}$ for $30 \mathrm{~min}$. (a) is the minor loops of the $\mathrm{Fe}_{50} \mathrm{Pt}_{50}$ film that was slowly cooled in a furnace and (b) is the minor loops of the $\mathrm{Fe}_{50} \mathrm{Pt}_{50}$ film quenched in ice water.

Figures 6(a) and 6(b) show the continuous minor loops of the $\mathrm{Fe}_{50} \mathrm{Pt}_{50}$ films annealed at $600{ }^{\circ} \mathrm{C}$ for 30 min with (a) furnace cooled and (b) quenched in ice water. These minor loops are obtained from VSM with $\mathrm{Ha}$ varied from 600 to 12000 Oe. It is clear that the $\mathrm{Fe}_{50} \mathrm{Pt}_{50}$ film quenched in ice water exhibits the domain wall pinning mechanism, and the $\mathrm{Fe}_{50} \mathrm{Pt}_{50}$ film that was slowly cooled in a furnace (cooling rate is about $4^{\circ} \mathrm{C} / \mathrm{min}$ ) exhibits the domain nucleation mechanism. ${ }^{6}$

${ }^{1}$ S. W. Yung, Y. H. Chang, T. J. Lin, and M. H. Hung, J. Magn. Magn. Mater. 116, 411 (1992).

${ }^{2}$ B. Zhang, M. Lelovic, and W. A. Soffa, Scr. Metall. Mater. 25, 1577 (1991).

${ }^{3}$ K. Watanabe, Mater. Trans., JIM 32, 292 (1991).

${ }^{4}$ A. Z. Men'shikov, Yu. A. Dorofeyev, V. A. Kazantsev, and S. K. Sidorov, Fiz. Met. Metalloved. 38, 505 (1974).

${ }^{5}$ J. P. Liu, C. P. Luo, Y. Liu, and D. J. Sellmyer, Appl. Phys. Lett. 72, 483 (1998).

${ }^{6}$ M. Watanabe, T. Nakayama, K. Watanabe, and K. Hiraga, IEEE Transl. J. Magn. Jpn. 8, 875 (1993) 